\title{
Consumo de carne y nutrición. Aspectos de su evolución histórica en Venezuela: 1609-1873 *
}

\author{
Jaime Torres Sánchez. \\ Universidad de los Andes. Mérida. Venezuela
}

Se examina el consumo de proteína animal en la evolución del régimen alimenticio y nutricional de Venezuela hasta 1873. De acuerdo al comportamiento del consumo neto, el régimen alimenticio fue relativamente estable y dependió de muy pocos productos: plátano-maíz-granos-carne. La carne experimentó un consumo creciente hasta la segunda mitad del XVIII, con una aguda caída en el siglo XIX. El régimen nutricional dependió así de las calorías del plátano y de los granos a fines del período. Tales tendencias pudieron ser características de toda la sociedad colonial y postindependentista latinoamericana. En una perspectiva comparativa, la alimentación venezolana no aparece tan excepcionalmente nutritiva, aunque en el siglo XVIII se hubieran alcanzado los máximos de consumo de carne per cápita, como lo indicaron los comtemporáneos. Tampoco los porcentajes de proteína animal parecen tan considerables.

En este artículo se presenta una discusión sobre la evolución del consumo de carne en Venezuela, en la larga duración. Este examen puede proporcionar informaciones históricas valiosas sobre el desenvolvimiento de los regímenes alimenticios y nutricionales, por la importancia de los componentes proteínicos animales en la calidad de la dieta.

El punto de partida es la sugerencia formulada por un estudio reciente que señala el alto valor nutricional de la "dieta criolla tradicional" del siglo XVIII y su deterioro a lo largo del siglo XIX. ${ }^{1}$ Sobre un ordenamiento crítico de los escasos datos existentes, se amplían estas consideraciones, desarrollándose la hipótesis de la disminución del consumo per cápita de carne durante el siglo XIX y su estabilización a un bajo nivel a comienzos del siglo XX. Las bases documentales son tres textos: dos libros del siglo XIX, escritos por observadores acuciosos, y un documento del XVIII, ${ }^{2}$ los que se analizan con una metodología que permite su comparación.

\footnotetext{
* Advertencia: Por razones de espacio en este artículo se han eliminado los alcances sobre Metrología y Metodología empleados en la construcción de las variables.

1 Lovera, José Rafael: Historia de la alimentación en Venezuela, Caracas, 1988, págs. 98-107.

2 Marón, Doctor Agustín: "Relación Histórico-Geográfica de la Provincia de Venezuela. 1775”, en Documentos para la Historia Económica en la Época Colonial. Viajes e Informes, compilador Arellano Moreno, A., Caracas, 1970, págs. 411-474. Este texto es utilizado por Lovera en su versión original del Museo Británico. Codazzi, Agustín: Resumen de la Geografía de Venezuela, Venezuela en 1841, I, II, Caracas, 1940. Tejera, Miguel: Venezuela pintoresca e ilustrada, I, II, (1875), Caracas, 1986.
} 
No se cuenta con estudios críticos sobre dichas fuentes que faciliten una evaluación sistemática de sus observaciones, pero en general, son textos bastante ricos en información, si se consideran con prudencia sus apreciaciones cuantitativas. Aunque sus datos sobre cantidades de alimentos consumidos parecen discutibles en muchos casos, suscitan hipótesis muy sugestivas para su examen futuro en estudios sobre fuentes directas.

En el Cuadro N. ${ }^{\circ} 1$ se presentan los cálculos sobre el consumo de carne. Desde un ángulo global la hipótesis que fundamenta la elección de las variables es la de que tal evolución está asociada a la disponibilidad de carne, al número de consumidores, al nivel de ingreso y las 'preferencias' de éstos por tal bien. Es decir, a la configuración de una economía ganadera y al desarrollo de un mercado interior. Tal modelo de relaciones supone intercambios monetarios y, por tanto, deja fuera de examen el autoconsumo. Por los caracteres de los datos utilizados y por el hecho de que hasta el primer decenio del XVII este consumo podría haber sido mínimo, ${ }^{3}$ el modelo es aplicable hasta 1609 con bastante realismo para toda la población española, aunque la población indígena, que incluía carne de res en su dieta, queda excluída. Para los restantes años las cifras son válidas para el contingente integrado al mercado colonial, excluyéndose los indígenas, aunque éstos ya no eran numéricamente importantes a fines del siglo XVIII. ${ }^{4}$

Las fuentes no hacen distinción entre autoconsumo y consumo de mercado y todas las evidencias apuntan hacia la existencia de un consumo marginal a los intercambios monetarios, fuera del área urbana de Caracas. En ellas simplemente se imputa un consumo con independencia de la forma bajo la cual se realiza. Por la importancia de los problemas de abastecimiento de carne hasta el siglo XVIII en esta ciudad, ${ }^{5}$ cabría deducir que, en buena medida, tal oferta pasaba por el circuito monetario urbano. En las zonas ganaderas, los Llanos, evidentemente esto no era así, pero a fines del

3 Hacia 1535, Coro importaba carne desde Santo Domingo (Arcila Farías, E.: El primer libro de la Hacienda Pública colonial de Venezuela: 1529-1539, Caracas, 1979, pág. 23), aunque ya en 1538 se constata la existencia de un hato en sus cercanías (ibídem, pág. 19). Hacia 1547 la relación entre ganadería, minería e ingresos era visible para Pérez de Tolosa (ídem, Hacienda y comercio en Venezuela, 1983, II, pág. 23). Ubicada esta ganadería en el área centro-costera, en condiciones de disponibilidad limitada de pastos y de costos elevados para la formación de un stock vacuno, era probable un alto grado de monetización de la actividad.

4 La población indígena era el $12 \%$ del total hacia 1800, según cálculos a partir de datos de Arcila Farías, E.: El régimen de la encomienda en Venezuela, Caracas, 1966, págs. 67-70.

5 Castillo Lara, Lucas G.: San Sebastián de los Reyes, I, Caracas, 1984, págs. 194-196. Para el siglo XVIII, Rodríguez Mirabal, Adelina C.: La formación del latifundio ganadero en los Llanos de Apure: 1750-1800. Caracas, 1987, págs. 168-169. 
período colonial su población, constituída por indios, negros y mestizos, era todavía minoritaria dentro de la población total: un $21 \% .{ }^{6}$ Este análisis supone que la variable "población consumidora de carne" excluye a la población indígena en el período colonial que, en virtud de las consideraciones que se hacen en el análisis, parece bastante razonable. Respecto al "consumo anual de reses", para 1578, 1609 y 1775 se iguala a la "cosecha", lo que parece realista pues la exportación de ganado "en pie" era muy poco probable. Para 1839 y 1873, el cálculo se hace en base al consumo total de carne estimado por las fuentes.

No obstante, el comportamiento de estas variables permite conclusiones tentativas. La masa ganadera de 1609 parece bastante baja pese al gran crecimiento absoluto, en casi treinta años, derivado de la baja cifra inicial. Hay indicios dispersos de que la masa ganadera real pudo haber sido mucho mayor, en tanto en este decenio comenzó la incorporación de las reses salvajes del territorio llanero. En 1608, en San Sebastián, un observador declaraba la existencia de "veinticinco mil cabezas arriba". Con todo, se podría aceptar la hipótesis de un lento crecimiento de esta economía ganadera, tomando como base la lenta evolución del consumo hasta 1609.

Después de ese año, aumenta el consumo no sólo por el incremento cuantitativo de la población consumidora, sino también por la probable mayor participación de la carne en la dieta y el aumento de la masa ganadera. De hecho, algunos datos dispersos indican que las 16 a 20 reses mensuales que consumía Caracas en 1578, aumentaron a 400 en $1670 .{ }^{8}$ Por lo demás, existen evidencias de un incremento del ingreso a fines del siglo XVI, pese a que al término de la década de los 80 , agotado el ciclo aurífero, la economía colonial entró en una prolongada crisis estructural. ${ }^{9}$

Entre 1578 y 1609, la tasa de crecimiento interanual de la población alcanzó un 3,0 a 3,5 en promedio, y el gasto medio, importaciones divididas por el número de habitantes, en un 1,5 a 2,0. El gasto medio creció menos que la población en esta fase de reestructuración económica, pero es

6 En 1800 la población total de Venezuela era de 394.891 y los Llanos tenían 82.949 habitantes. Ver Arcila Farías: El régimen ..., págs. 67-70.

7 Castillo Lara: San Sebastián ..., I, pág. 47.

8 Ibídem, pág. 195.

9 A partir de 1586-1590 las cifras de producción de oro, principal exportación, caen abruptamente, haciéndose deficitarios los saldos de la balanza comercial. El comercio externo se reestructuró de tal modo que sólo en el primer decenio del XVII la actividad exportadora se recuperó, primero con el tabaco y después con los cueros de res, hasta 1630. Sobre la base de datos Arcila Farías, E.: Hacienda y ... , II, págs. 20-21, 37, 42-43, 47; ídem, Hacienda y comercio de Venezuela en el siglo XVII: 1601-1650, V, 1986, págs. 118-119. 
significativo que se haya duplicado en un período de crisis, ${ }^{10}$ con lo que el consumo pudo crecer. A partir de 1581 hubo un incremento en la capacidad impositiva ${ }^{11} \mathrm{y}$ un aumento del consumo productivo. ${ }^{12} \mathrm{Y}$ si el saldo del comercio externo tuvo fluctuaciones positivas y negativas en la primera mitad del siglo XVII ${ }^{13}$ permaneciendo estancado el gasto per cápita, los agricultores y comerciantes caraqueños pudieron, al parecer, mejorar su participación en el ingreso. Controlaban en todas sus fases la agricultura del cacao pues invirtieron unos 500.000 pesos en esclavos negros, y formaron una flota mercante. ${ }^{14}$ Durante todo el siglo XVII la exportación de cacao respondió a una tendencia de larga duración al alza del precio del producto. ${ }^{15}$ Todo ello indicaría una elevación del ingreso de la colonia durante el siglo XVII.

Independientemente de las fluctuaciones del ingreso global durante el siglo XVIII ${ }^{16}$ y de sus efectos en el gasto, parece bastante probable que el consumo per cápita de carne durante su segunda mitad haya sido el más elevado del período colonial. Diversas apreciaciones de contemporáneos enfatizan el fuerte contenido cárnico en el régimen alimenticio. Para Marón, en 1775 "todas las personas de esta provincia sin distinción de edad ni sexo, comen carne por lo menos tres veces al día, así por la costumbre como por valer barata". Lo que tenía lugar todo el año pues "las vigilias......regularmente no se guardan en los llanos, y en Caracas siempre hay el mismo consumo en la Cuaresma". De tal consumo no se excluía ni siquiera a los muchachos "porque éstos almuerzan, comen, meriendan y cenan carne asada y chorote". ${ }^{17}$

10 Cálculos en base a datos de Arcila Farías: Hacienda y ..., 1986, págs. 47-55, 133 (Cuadro № 1); ídem, Hacienda y ..., 1983, II, págs. 37, Cuadro N. ${ }^{\circ} 4$.

11 El balance de Real Hacienda es positivo en 1581-1583, 1598-1600. En base a datos de Arcila Farías: Hacienda y ..., 1983, II, pág. 37, Cuadro N. ${ }^{\circ}$ 4; pág. 116, Cuadro N. ${ }^{\circ} 11$.

12 Entre 1584-1600 se introdujeron 1.110 esclavos por valor neto de 183.453 pesos de oro fino, de los cuales sólo entre 1586-1590 se pagó el 85,47\%, cuando en el mismo período la producción de oro fue de 7.137 pesos. Ver: Arcila Farías: Hacienda y ..., 1983, II, pp, 65, 38. La primera cifra se ha convirtió a pesos de oro fino en base a equivalencia de pág. 236. $42-43,47$.

13 Cálculos en base a datos de Arcila Farías: Hacienda y ..., 1983, II, págs. 20-21, 37,

14 Arcila Farías: Hacienda y ..., 1986, págs. 225-226.

15 En base a datos de exportación y precios reducidos a medias anuales, de Arcila Farías: Economía colonial de Venezuela, Caracas, 1973, I, págs. 153-157, 265-323, 326-327; Brito Figueroa, F.: La estructura económica de Venezuela colonial, Caracas, 1983, pág. 215.

16 Hay una tendencia a la baja del precio del cacao venezolano en los mercados de Amsterdam y Caracas con posterioridad a 1731-1740. Ver Romano, R.: Cuestiones de historia económica latinoamericana, Caracas, 1966, pág. 39.

17 Marón, Agustín: Documentos ..., BAHN, 93, 1970, pág. 447. 


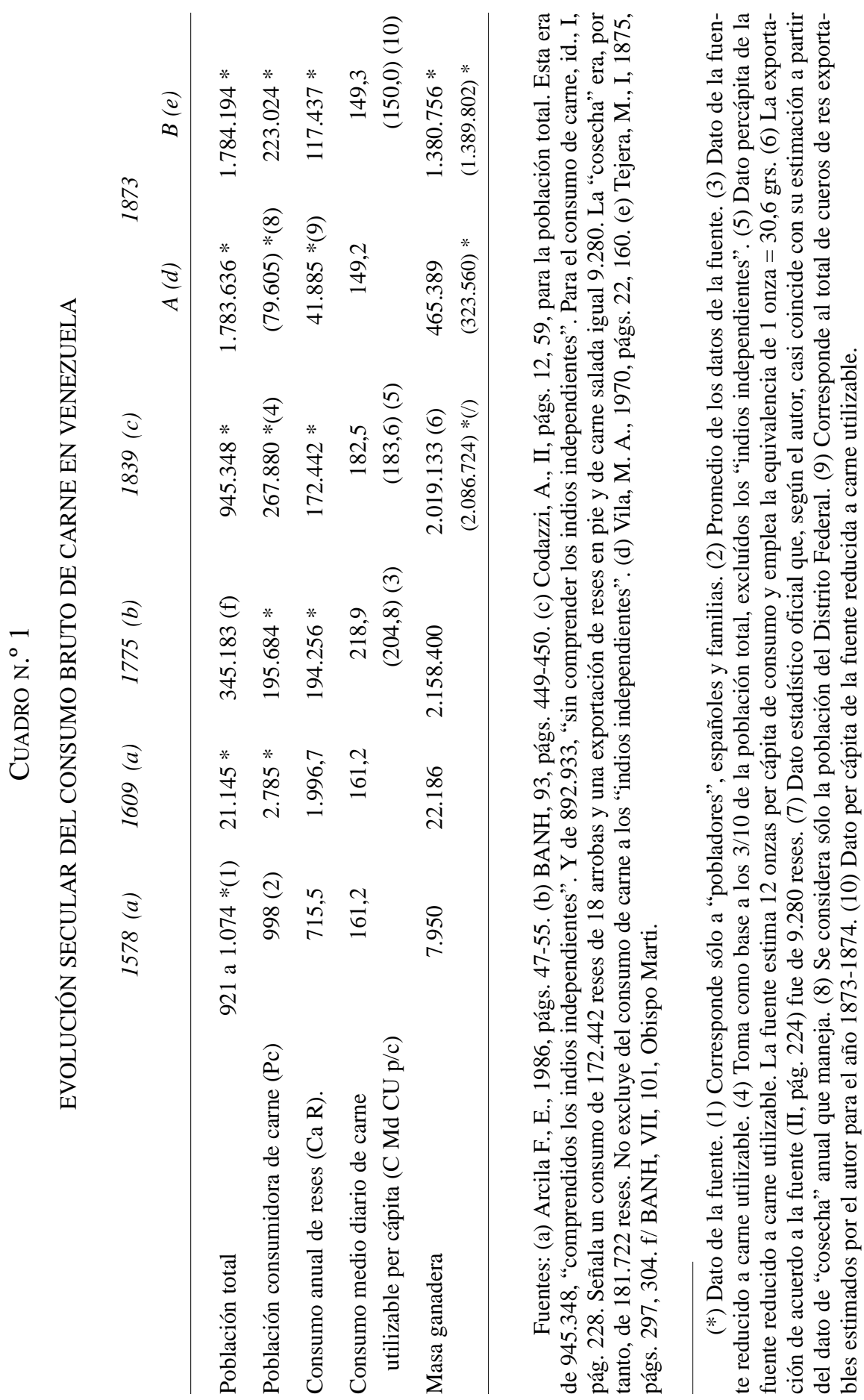


Debe advertirse que si el consumo per cápita de 1578 y 1609 se medía por la población que accedía al mercado, los datos de 1775 son poco claros al respecto. La fuente señala que este consumo incluía a los indios y parece extender esta consideración al consumo de los restantes productos. No obstante, la diferencia entre ese número de consumidores y la población total, según la otra fuente citada en el Cuadro N. ${ }^{\circ} 1$, podría indicar que incluyó sólo una pequeña fracción de indígenas en sus cálculos. Se sabe que éstos incorporaron rápidamente la carne de res a su dieta, ${ }^{18}$ lo que querría decir que los cálculos de la masa ganadera estarían infravalorados. La conclusión respecto a este producto, sin embargo, está lejos de ser aventurada, pues un buen observador como Humboldt no sólo señalaba este alto consumo, sino que establecía su directa relación con el "bienestar de los habitantes", aunque hacia 1800 éste parecía estar disminuyendo pues detectaba una fuerte reducción de ganado. Para 1799, se deduce de sus observaciones que la ciudad de Caracas tenía un consumo per cápita diario de carne utilizable por res de 196 gramos y para 1800, Nueva Barcelona y Puerto Cabello, 151,6 y 183,8 gramos, respectivamente. ${ }^{19}$

Al parecer, la disminución de la masa vacuna fue correlativa al aumento de la población en todo el país durante el siglo XIX, ${ }^{20}$ de lo que cabe deducir que el consumo de carne había disminuido en sus niveles medios respecto al siglo anterior. Para 1839, Codazzi proporciona las cifras de población, masa ganadera y consumo medido en número de reses. Tal

18 En 1648 se dejaba constancia de cómo en un hato cercano a Barinas, en una entrevista entre autoridades españolas e indios de los Llanos, éstos "se rretiraron a sus ramadas a disponer un novillo o dos que tenían ahumados o tostados a fuego lento para el sustento de aquel día", en Carvajal, Jacinto de: Relación del Descubrimiento del río Apure hasta su ingreso en el Orinoco, (1648), CaracasMadrid, 1956, pág. 73. En 1653, un cacique indio declaraba que si atacaban los hatos "es por comer vacas", en Armas Chitty, J. A.: Historia del Guárico (1532-1800), I, 1979, págs. 223-225. En 1659, en una Capitulación entre el gobernador de Venezuela y Tomás de Ponte, éste se obligaba a proveer de carne de vaca a unos indios del Llano pacificados. En: BANH, Misión de los Capuchinos en los Llanos de Caracas,. I, 111, págs. 289-295. A fines del siglo XVII y durante el XVIII todas las misiones en el Llano tenían rebaños propios para la alimentación de los indios. Hacia 1701, un capuchino acusaba a los españoles de las villas de "nunca o rara vez les pagan su trabajo sino en carne". En : BANH, Misión de los Capuchinos en los Llanos de Caracas, II, 112, pág. 23.

19 Humboldt, A. de: Viaje a las regiones equinocciales del nuevo continente, Caracas, 1985, V, pág. 171: "Como el consumo de carne es inmenso en este país, la disminución de los animales influye más que en cualquier otra parte, sobre el bienestar de los habitantes".

20 En Izard, Miguel: Series estadísticas para la historia de Venezuela, Mérida, Venezuela, 1970, pág. 96, se advierte que durante el siglo XIX, y hasta 1920, el total de vacunos del país bordeó la cifra alcanzada en 1775, excepto en $\operatorname{los}$ años $1847,1858,1886,1887$ y 1888, en los que fue sobrepasada. La población total, en cambio como está bien establecido, creció sostenidamente a lo largo del siglo XIX. 
consumo medio habría bajado respecto a las cifras del siglo XVIII, pues el mismo autor estima una media anual de 12 onzas. ${ }^{21}$ Es segura esta disminución, por tanto, aún cuando la masa ganadera se había recuperado del impacto de la guerra de la Independencia. La proporción de la población consumidora de carne, reducida a 3/10 del total, podría indicar que Codazzi sólo estimaba a aquella que compraba la carne, lo que en condiciones de caída del ingreso global con posterioridad a las guerras de la Independencia era altamente probable. Es posible que el resto de la población, en la cual los indígenas eran minoría, apelara al autoconsumo y tendiera a establecer su balance proteínico animal por la vía de la caza y la pesca.

La situación se deterioró hacia 1873, pues para ese año, según una de las fuentes citadas en el Cuadro N. ${ }^{\circ} 1$, la masa ganadera era de 331.060 cabezas y la población total casi se había duplicado. Evidentemente el consumo anual per cápita se habría reducido respecto a 1839. Informaciones contemporáneas confirman esa hipótesis para Caracas, que era el mercado más importante. Una observadora afirmaba que: "El consumo de carne de carnicería está muy restringido entre la población de Caracas. No se benefician diariamente para una población de 50.000 almas, más de un promedio de 45 animales: bueyes, vacas, corderos, marranos, etc. Este comercio aunque poco considerable, no deja de producir gruesos beneficios". ${ }^{22}$ Lo que significaba un consumo medio diario per cápita de carne utilizable de 93,15 grs. suponiendo que todos los animales fueran reses. Cálculos contemporáneos para el Distrito Federal lo hacían llegar en 1874 a 130 grs. per cápita, haciéndose notar que este promedio hacía abstracción de la concentración del ingreso. ${ }^{23}$ Similar situación evidenciaba el interior cafetalero andino, pues el Táchira en el año 1873, con 68.619 habitantes, consumía sólo 8.000 reses anuales, ${ }^{24}$ lo que equivalía a 33 gramos diarios per cápita.

Por consiguiente, la curva de consumo cárnico bruto medio podría haber tenido un comportamiento característico de lento y bajo nivel hasta comienzos del siglo XVII, de crecimiento rápido hasta un máximo en la segunda mitad del siglo XVIII, disminuyendo durante la segunda mitad del XIX hasta alcanzar, en el mejor de los casos, el mismo nivel de consumo de fines del siglo XVI.

21 Codazzi: Resumen ..., I, pág. 222.

22 Citado en Vila, M. A.: La geografía humano-económica de la Venezuela en 1873, Caracas, 1970 , pág. 255.

23 Ibídem, pág. 84.

24 Villafañe, J. G.: Apuntes estadísticos del Estado Táchira, (1873), Caracas, 1960, págs. 49-50, Apéndice. 
Vale la pena intentar examinar la significación del consumo de este alimento en relación al de otros productos. Un intento de acercamiento a lo que podría haber sido la evolución del régimen alimenticio y nutricional entre fines del siglo XVIII y la segunda mitad del XIX lo proporcionan los datos del Cuadro N. ${ }^{\circ} 2$.

Cabe insistir en que tales datos se han obtenido por procesamiento de las observaciones de las fuentes sobre la cantidad de algunos productos consumidos por persona. En ellas se asume que son representativos en la alimentación de un individuo, o de ciertos grupos de éstos. No se trata de una ración media, aunque para el autor de 1775 podrían interpretarse sus observaciones en esa dirección. Al parecer, no es un consumo nominal, medido a través de los gastos de consumo en el mercado, sino un consumo real, aún cuando Codazzi imputa finalmente su valor monetario. Lo que querría decir que las variaciones del consumo de tales bienes, no necesariamente dependían tan sólo de las fluctuaciones del ingreso personal.

\section{CUADRO N. ${ }^{\circ} 2$}

EVOLUCIÓN DEL CONSUMO Y CALORÍAS ALIMENTICIAS PARA DIVERSOS PRODUCTOS. VENEZUELA: 1775, 1839 Y 1873

$1775 \quad 1839 \quad 1873$

\begin{tabular}{lccrrrr} 
Alimentos & $\begin{array}{c}\text { Consumo } \\
\text { grs. }\end{array}$ & $\begin{array}{c}\text { Calorías } \\
\text { kcals. }\end{array}$ & $\begin{array}{c}\text { Consumo } \\
\text { grs. }\end{array}$ & $\begin{array}{c}\text { Calorías } \\
\text { kcals. }\end{array}$ & $\begin{array}{c}\text { Consumo } \\
\text { grs. }\end{array}$ & $\begin{array}{c}\text { Calorías } \\
\text { kcals. }\end{array}$ \\
\hline Cacao & 28,9 & 124,1 & 5,1 & 21,9 & 6,6 & 28,1 \\
Café & - & - & 5,1 & - & 38,9 & - \\
Plátano & - & - & 656,9 & 922,1 & 1079,9 & 1515,8 \\
Máiz & 609,9 & 1116,7 & 368,0 & 673,4 & 399,9 & 732,3 \\
Casabe & 181,1 & 592,8 & 54,3 & 177,8 & 94,5 & 309,3 \\
Papa & - & - & 111,2 & 77,0 & - & - \\
Papelón & 63,0 & 224,3 & 21,0 & 74,8 & 219,2 & 780,3 \\
Azúcar & - & - & - & - & 19,7 & 73,1 \\
Trigo & - & - & 20,3 & 66,6 & 40,7 & 133,3 \\
Granos & 106,8 & 119,2 & 129,2 & 144,2 & 1311,9 & 1463,8 \\
Arroz & 106,8 & 100,0 & - & - & - & - \\
Carne & 168,3 & 391,1 & 45,2 & 107,2 & 38,0 & 142,5 \\
Queso & - & - & 24,3 & 79,9 & 38,4 & 126,0 \\
\hline Total & & $2.668,20$ & & $2.344,90$ & & $5.304,50$
\end{tabular}

Fuentes. Tablas I, II, III 
Una posibilidad de análisis es examinar la evolución del consumo neto, como indicador del "régimen de alimentación", y de los valores energéticos, calorías alimenticias, como indicadores del "régimen nutricional". En el cuadro siguiente presentamos la estructura por rangos del primero.

\section{CUADRO N. ${ }^{\circ} 3$}

EVOLUCIÓN SECULAR DEL RÉGIMEN DEL ALIMENTACIÓN. VENEZUELA

\begin{tabular}{clll} 
Rangos & 1775 & 1839 & 1873 \\
\hline 1. & Maíz & Plátanos & Granos \\
2. & Casabe & Maíz & Plátanos \\
3. & Carne & Granos & Maíz \\
Papelón \\
4. & Granos & Casabe & \\
& Arroz & & \\
5. & Papelón & Carne & Casabe \\
6. & Cacao & Queso & Carne \\
7. & & Papelón & Trigo \\
8. & & Trigo & Café \\
9. & & Cacao & Queso \\
10. & & Café & \\
11. & & & Azúcar \\
& & & Cacao
\end{tabular}

Fuentes: Cuadro N. ${ }^{\circ} 2$.

Para 1775 la fuente no proporciona el consumo medio de plátano, producto de gran importancia en la dieta del siglo XIX, aunque se señala que se comía de variadas formas: “... lo comen cocido en la olla, asado y frito con jamón, o carne salada, y de otros muchos modos...". También se menciona la utilización de la variedad 'dominico' ${ }^{25}$ Sin embargo, al parecer su importancia era considerada inferior a la de la yuca, de la cual se extraía el 'cazabe', "que es el pan más gustoso". ${ }^{26}$

25 BAHN, 93, 1970, Documentos ..., pág. 432.

26 Ibídem, pág. 438. 
Se conoce la frecuencia asignada al consumo de carne y cacao en este año, cuya asociación está mencionada expresamente: "El chocolate ... es tan común en esta provincia, que todas las personas lo toman, sin distinción de clases ni edad, mediante esta costumbre, y de tomarlo por la mañana, a la tarde y a la noche.... ${ }^{27} \mathrm{Al}$ café no se le menciona como bebida aunque su cultivo está señalado. ${ }^{28}$ Para beber el chocolate se usaba el papelón, “... además del que comen con queso, y otras cosas". ${ }^{29}$

$\mathrm{El}$ arroz era usual en la mesa "por lo mucho que se coge y consume". ${ }^{30}$ Los frijoles estaban considerados como representativos de las legumbres que se comen "así en la olla como en potajes", de las cuales había una cierta variedad: arroz, caraotas, quinchonchos, judías, arvejas, guisantes, no siendo comunes los garbanzos. ${ }^{31}$ Se mencionan variadas frutas, para comer en dulce, en bebida o para utilización como remedio, y raíces comestibles, todas las cuales se comían "en la olla", batatas, apios, patatas, ñame, ocumo, layrenes, mapueyes..$^{32}$ Eran conocidos también una gran variedad de pescados y de "anfibios" tales como lapas, cachicamos, y morrocoyes. ${ }^{33}$ Llama la atención que no se mencione al cochino como fuente de carne ni a la manteca, ${ }^{34}$ aunque se sabe que este animal acompañó a los europeos desde el inicio de las conquistas del Nuevo Mundo.

La confrontación de estas apreciaciones con los cálculos de este trabajo, pone en evidencia las creencias corrientes sobre el régimen alimenticio en 1775. No obstante la significación que se le asignaba, la asociación cacao-carne era secundaria dentro del consumo. Sorprende el contraste entre la importancia asignada al consumo de cacao y el rango ocupado por éste en la estructura alimenticia. Considerado en el tiempo su importancia disminuye más aún, pudiéndose asociar tal hecho a la aparición del café como bebida. En la región llanera se sabe que durante la primera mitad del siglo XIX la bebida usual, por lo menos para las mujeres, era el "mate". ${ }_{35}$

27 Ibídem, pág. 448.

28 Ibídem, pág. 436.

29 Ibídem, pág. 448.

30 Ibídem, pág. 478.

31 Ibídem.

32 Ibídem, págs. 433-438.

33 Ibídem, págs. 443-445.

34 En Ibídem, pág. 449, se menciona al "aceite común" en un texto que parece intercalado, pues la enumeración de la que forma parte no tiene vínculos lógicos con el párrafo antecedente y el posterior.

35 Vawell, R.: Las sabanas de Barinas, BANH, 10, Caracas. 1973, pág. 91. 
Sin duda que el patrón alimenticio característico a lo largo de todo el período aparece centrado en torno a muy pocos productos: plátano-maízgranos-carne, y posee una relativa estabilidad. En cambio, el de quesopapelón-cacao exhibe una gran variabilidad. El papelón aparece con una importancia creciente junto con los granos durante el siglo XIX, ${ }^{36}$ aunque era importante ya en el siglo anterior ${ }^{37}$ Sin considerar la papa y el trigo, ${ }^{38}$ los cambios individuales de mayor significación parecen ser los del cacao, carne y granos.

El maíz era "el principal sustento de las Repúblicas, así de españoles como de naturales", ya en $1626 .{ }^{39}$ En el siglo XIX mantiene su significación aunque disminuye su cuantía desplazado por los granos. Con ello cobra más fuerza la hipótesis de la continuidad del consumo de plátanos, pues si sólo en 1839 y 1875 se precisa documentalmente su consumo per cápita, de hecho en 1775 también se le señala como alimento popular. Es probable que su incorporación a la dieta fuera tan habitual que, por ello mismo, no hubo interés en 1775 en calcular su consumo, además de que crecía virtualmente silvestre. Aunque cabría también sostener, en otra hipótesis, que su importancia tendió a acrecentarse en el siglo XIX debido a los cambios en la alimentación.

La persistencia de los patrones alimenticios pone en evidencia la significación del aporte en bienes de consumo de la agricultura de "conuco"40 y de su fundamento económico esencialmente extractivo en una actividad de trabajo simple. Los productos de mayor variabilidad en el régimen eran los que requerían, en cierta medida, de coordinaciones sociales complejas,

36 Para Humboldt (Viaje a ..., T. III, págs. 131, 133): "El ser más pobre come papelón, como en Europa se come queso", siendo su consumo como el de azúcar, "tan enorme, que la exportación ha sido hasta ahora en absoluto nula".

37 Lovera: Hacienda ..., pág. 77.

38 Es posible que hacia esa fecha el trigo tuviera un área de circulación más extensa derivada de la importación de harina de trigo, pues en carta al Honorable Sr. presidente del Consejo de Ministros, Caracas, 5 de mayo de 1829, se indicaba: "la abundante introducción de muchos artículos que antes eran la ocupación de familias pobres", atribuyéndola tanto a la ausencia de leyes adecuadas sobre el comercio exterior como al atraso industrial. Señalaba la circulación de jabón extranjero y de harina de trigo norteamericana. En Banco Central de Venezuela: La Hacienda Pública de Venezuela en 18281830, Misión de José Rafael Revenga como Ministro de Hacienda, Caracas, 1953, pág. 95.

39 Citado en: Castillo Lara: San Sebastián ..., I, pág. 182.

40 El papel de esta agricultura de conuco, en manos de indígenas, mestizos y negros esclavos, en la provisión de bienes de consumo está señalado en Izard, M.: "La agricultura venezolana en una época de transición”, Boletín Histórico, n. ${ }^{\circ}$ 28, Venezuela, 1972, págs. 24-25. También Lovera: Historia..., págs. 87-88. Es posible que su función en la provisión de bienes en los mercados locales esté subestimada. 
como la ganadería, ${ }^{41}$ de lo que derivaba la sensibilidad de éste a los cambios sociales y económicos.

No obstante la nada sorprendente estabilidad de este régimen, ${ }^{42}$ revela una readecuación en el tránsito hacia el siglo XIX en las tendencias que revisten los productos individuales. El maíz, casabe, carne y cacao, alimentos característicos de la dieta colonial, tienden a perder importancia. En cambio, los granos, papelón y café, adquieren una mayor significación en la dieta postcolonial. Los cambios individuales de mayor impacto en el régimen alimenticio son, sin duda, los del cacao, carne y granos. En 1839 esto fue advertido por Codazzi, quien manifestaba "se prefiere dar a comer a los peones de las haciendas de estas nutritivas legumbres (granos, menestras, NJT), en lugar de carne, aunque ésta tiene un precio equitativo en el mercado". ${ }^{43}$ En 1875 también se apuntaba al hecho de que los granos, cultivados en una gran variedad, "sirven de principal sustento a los campesinos". ${ }^{44}$

Desde un ángulo histórico, tales cambios reflejan las modificaciones económicas que estaba experimentando la economía venezolana durante la primera mitad del siglo XIX. Por una parte, el desplazamiento exportador desde el cacao al café, que había comenzado ya a fines del siglo anterior. ${ }^{45}$ Y, por otra, las fluctuaciones coyunturales a la baja de la masa ganadera, con motivo de la guerra de la Independencia, con el consiguiente efecto en la provisión de carne y en la desarticulación agrícola, por la ausencia de animales de labor y transporte, ${ }^{46}$ aunque todavía tal sector no entraba en declinación como lo haría en la segunda mitad del siglo.

El proceso de cambio del régimen nutricional se puede apreciar en el siguiente cuadro:

41 En Torres Sánchez, J.: Evolución de la economía ganadera de los Llanos CentroOccidentales. El Alto Apure en 1910: renta y ganancia en 'El Calman' y 'La Balza', Universidad de los Andes, Venezuela, 1990 (inédito), se formula la hipótesis de que los distintos factores explicativos del estancamiento ganadero de la segunda mitad del siglo XIX, apuntado por los contemporáneos, particularmente la Guerra Federal, sólo podrían haber tenido efectos de largo plazo en caso de que hubieran afectado a las redes sociales que sostenían el "trabajo de llano". Este requería de una compleja coordinación social.

42 La estabilidad secular de los regímenes alimenticios ha sido detectada por toda la historiografía de la alimentación. Ver Annales, 1975, Núms. 2-3, págs. 431-442.

43 Codazzi: Resumen ..., I, pág. 185.

44 Tejera: Venezuela ..., pág. 287.

45 Izard, M.: "El café en la economía venezolana del XIX. Estado de la cuestión”. Valencia, 1973, págs. 207-208.

46 Izard: "La agricultura ...", págs. 42-44. 
CONSUMO DE CARNE Y NUTRICIÓN EN VENEZUELA: 1609-1873

Cuadro N. ${ }^{\circ} 4$

EVOLUCIÓN SECULAR DEL RÉGIMEN NUTRICIONAL. VENEZUELA

1775

1839

1873

\begin{tabular}{|c|c|c|c|c|c|c|}
\hline & Alimentos & $\%$ & Alimentos & $\%$ & Alimentos & $\%$ \\
\hline \multirow[t]{5}{*}{ I. } & Maíz & 41,8 & Plátanos & 39,3 & Plátanos & 28,6 \\
\hline & Casabe & 22,2 & Maíz & 28,7 & Granos & 27,6 \\
\hline & Carne & 14,7 & & & Papelón & 14,7 \\
\hline & & & & & Maíz & 13,8 \\
\hline & & 78,7 & & 68,0 & & 84,7 \\
\hline \multirow[t]{8}{*}{ II. } & Papelón & 8,4 & Casabe & 7,6 & Casabe & 5,8 \\
\hline & Cacao & 4,7 & Granos & 6,2 & Carne & 2,7 \\
\hline & Granos & 4,5 & Carne & 4,6 & Trigo & 2,5 \\
\hline & Arroz & 3,8 & Queso & 3,4 & Queso & 2,4 \\
\hline & & & Papa & 3,3 & Azúcar & 1,4 \\
\hline & & & Papelón & 3,2 & Cacao & 0,5 \\
\hline & & & Trigo & 2,8 & & \\
\hline & & & Cacao & 0,9 & & \\
\hline
\end{tabular}

Fuentes: Cuadro N. ${ }^{\circ} 2$.

El régimen de nutrientes aparece casi dominado por los mismos productos característicos del régimen de alimentación, con lo cual la aportación de calorías fisiológicas pudo depender de muy pocos productos, los que proporcionaban entre el $70 \%$ y el $85 \%$ de éstas. Aún más, en este primer grupo la tendencia fue a depender de las calorías del plátano y los granos, descendiendo drásticamente el consumo del maíz. Y si la carne figuraba en la dieta colonial, en el siglo XIX descendió su aportación calórica a niveles mínimos. La fragilidad nutricional de la alimentación post independentista contrasta con la del siglo XVIII. La readecuación del régimen de alimentación parece haber estado asociada a una pérdida de calidad de la dieta.

Vale la pena hacer una consideración respecto de los totales calóricos que suministraban la energía fisiológica (ver cuadro N. ${ }^{\circ} 2$ ). Debe recordarse que para 1775 en la 'persona-día' se consideraba hasta los "muchachos". Las calorías del cálculo son evidentemente excesivas si se comparan con los requerimientos medios para una persona-día de la población venezola- 
na actual, estimados en 2.200. Sin embargo, el desgaste energético promedio para la época tuvo que haber sido superior. Y dentro de éste, es probable que las diferencias entre los niveles de la actividad física de hombres y mujeres no hayan sido muy grandes para un porcentaje mayoritario de la población.

Al margen de las inexactitudes posibles de las observaciones de 1775, tal visión de la alimentación del venezolano medio si comportaba una dieta excesivamente rica en calorías, de acuerdo a los requerimientos medios actuales, no lo parecería tanto de acuerdo a las consideraciones hechas. En otros términos, desde este ángulo, es posible que la ración colonial atribuida por Marón hubiera sido adecuada en términos de totales calóricos alimenticios.

Los datos posteriores indican una disminución de las calorías en 1839 y un aumento sustancial de ellas con posterioridad, pero con un empobrecimiento de la calidad nutricional, en tanto la relación proteína animal/prótidos tendió a caer violentamente, como se advierte en el cuadro siguiente:

\section{CUADRO N. ${ }^{\circ} 5$}

FÓRMULAS DIETÉTICAS DE RACIONES ATRIBUIDAS DE DISTINTOS AÑOS. VENEZUELA (PORCENTAJES)

\begin{tabular}{lccr} 
& 1775 & 1839 & 1873 \\
\hline Prótidos & 10 & 8 & 11 \\
Lípidos & 19 & 10 & 7 \\
Glúcidos & 72 & 82 & 83 \\
Proteína animal/Prótidos & 53 & 21 & 9
\end{tabular}

Fuentes: Tablas I, II, III.

En líneas generales, la comparación indicaría un aumento de la ingestión de glúcidos con una disminución sustancial de los lípidos, lo que se explicaría por la evolución del régimen alimenticio. En éste, tendió a aumentar la importancia de los granos y a disminuir la de la carne. Se advierte que en todo ese largo período el consumo de carne era fundamental en los equilibrios nutricionales, lo que se puede asociar a la importancia que se asignaba a ese alimento en la mesa diaria. Debe insistirse, sin 
embargo, en que la participación de los lípidos está subvaluada porque en las fuentes no se considera el consumo de grasas animales y aceites vegetales. La inclusión de éstos seguramente habría alterado la relación entre lípidos/glúcidos, aunque no lo suficiente, para que la presencia de los glúcidos no fuera predominante. Por lo demás, este rasgo se encontrará presente en los resultados de las primeras encuestas sobre nutrición que se harían en la década del 30 y el 40 del siglo XX. ${ }^{47}$

Se puede apreciar de manera específica la significación de tales valores si se los compara con los aportes calóricos porcentuales recomendables de acuerdo a estudios actuales, ${ }^{48}$ sintetizados en la fórmula:

$$
[10 / 13-25 / 30-58 / 65]
$$

En las fórmulas dietéticas para los tres años, el consumo de glúcidos respecto a los requerimientos era muy alto, aunque la provisión de proteínas parece bastante inestable con descenso en la cantidad de lípidos. Sin embargo, el porcentaje de complemento de proteína animal respecto a la total, adecuado inicialmente, tendió a disminuir drásticamente en el siglo XIX. Considerando que en la alimentación diaria de 1775 se consumían otros productos vegetales y animales, según la fuente, es posible deducir que, en términos cualitativos, esta dieta bien podría haber estado más cercana a un grado de adecuación normal de requerimientos/disponibilidad de nutrientes. ${ }^{49}$

La situación cambió con posterioridad, pues se advierte hasta 1873 la disminución del aporte proteico animal. El desequilibrio glúcido/proteico aparece, así, como rasgo de amenaza creciente.

Es probable, sin embargo que, si tales tendencias se hubiesen dado, pudieran haber operado de manera diferente según las regiones. Hay evidencias que confirmarían estas apreciaciones. En las áreas llaneras, centros de la economía ganadera, se cuenta con observaciones que fortalece-

47 Vélez Boza, F.: "La alimentación y la nutrición en Venezuela". Revista de Sanidad y Asistencia Social, volumen XIII, n. ${ }^{\circ} 1$ y 2, Caracas, 1948, págs. 143-145, según encuesta sobre 500.000 habitantes en 1938, otra sobre 433 personas en Caracas en 1940, un estudio sobre el medio rural con 2.500 personas en 1940, y otra sobre la clase trabajadora de 1943.

48 Bengoa, J.M.: "Calorías y una visión de conjunto", en CAVENDES: La nutrición ante la crisis, Caracas, 1987, pág. 331.

49 Guerra, M.: “Alternativa nutricional deseable de proteínas”, Ibídem, págs. 294-295. El nivel deseable era de un 57\% en 1977, según estudios. Un nivel aceptable es uno no inferior al 30\%. Según la autora, el exceso de energía permite reducir los requerimientos proteicos. 
rían la hipótesis de deterioro cualitativo de la dieta, aún cuando allí siguió siendo la carne un elemento básico de la alimentación. Hacia 1846-1847, Ramón Páez apuntaba que los llaneros "no consideran como esencial el pan, en su lugar un trozo de hígado cocido que les agrada más", hasta "se privan...de la carne fresca...por ser naturalmente sobrios, mirando la leche y la mantequilla como alimentos sólo propios para niños". ${ }^{50}$ En general, eran una mano de obra disciplinada y frugal: "Escasamente equipados: pagados pobremente; y con la sencilla comida de los Llanos por ración...". ${ }^{51}$ En el período de trabajo en los hatos, la alimentación se subordinaba a las tareas. Por la mañana, antes de iniciar los "trabajos de sabana", sólo se tomaba café sin leche, de acuerdo a la costumbre. ${ }^{52}$ Leche y mantequilla se estimaban alimentos de mujeres y niños, aunque los visitantes, como el hijo de Páez, no tenían reparos en utilizarlos: se recomendaba mezclar el café y la leche con maíz tostado para resistir las largas jornadas. ${ }^{53}$

En el Apure, en el hato San Pablo, diariamente se mataba un animal para el consumo, que se comía asado, sin legumbres ni pan, siendo considerada un lujo la arepa. No parecía ésta una situación habitual, pues según Páez, "se privan hasta de la carne fresca", lo que hace pensar que la carne seca era de uso regular. ${ }^{54}$ Como el queso era artículo muy apetecido, ${ }^{55}$ posiblemente la alimentación de trabajo la constituía carne seca, papelón y queso, la que en el caso de un domador de caballos le habría permitido llegar a los setenta años de edad..$^{56}$

Es posible que tal alimentación hubiera sido habitual en el Llano durante el siglo XVIII, pues corresponde también a las observaciones hechas por Humboldt en $1800^{57}$ y por José Antonio Páez hacia $1810 .{ }^{58}$ En cambio, la visión de un viajero alemán que en 1868 cruzó los Llanos apun-

50 Páez, R.: Escenas rústicas en Sur América o La vida en los llanos de Venezuela, (1862), Caracas. 1973, págs. 47-48.

51 Ibídem, pág. 287.

52 Ibídem, pág. 48.

53 Ibídem, pág. 149. En el mismo sentido, Mendoza, D.: El llanero (Ensayo de Sociología Venezolana), Buenos Aires, 1947, pág. 109.

54 Ibídem, págs. 47-48.

55 Ibídem, pág. 49.

56 Ibídem, pág. 93. Hacia 1857, en los Llanos Centrales, era común la utilización de carne seca, papelón, queso y caraotas negras. Ver: Rosti, Pal: Memorias de un viaje por América, (1861), Caracas, 1968, págs. 167, 174, 178 y 188.

57 Humboldt: Viajes ..., III, pág. 225.

58 Páez, J. A.: Autobiografía, Caracas, (sin fecha), I, págs. 6-7. 
ta hacia un empobrecimiento de la comida. Señalaba que en Ortiz la llegada de un transporte de ganado, después de mucho tiempo, había generado una verdadera conmoción pública. ${ }^{59}$ En Calabozo, "en los viejos y buenos tiempos reinaba también aquí un tráfico de importancia ...". Se trataba de poblados ubicados en plena zona ganadera. El régimen de alimentos parecía no haberse modificado en su composición, pero algunos de sus componentes merecían significativos comentarios: "El elemento básico de las provisiones al menos para el venezolano - es carne recién beneficiada y luego salada que se desprende de las costillas y se cuelga y extiende al sol para secar... la cual tiene un aspecto negro y asqueroso" ${ }^{60}$ Después de la carne venía en importancia el casabe y el papelón, agregándose café y "como artículo de lujo un poco de queso......". ${ }^{61}$ La desarticulación de la actividad ganadera y su efecto en la fabricación del queso era, posiblemente, lo que había llevado a convertir un producto básico de la dieta llanera en un producto "de lujo".

Pero no sólo cabe establecer limitaciones regionales a tales posibles tendencias, sino que conviene precisar el ámbito de significación de los universos poblacionales a los cuales están referidos los cálculos. Para 1775, Marón consideraba una población consumidora total de 195.684 personas, lo que difiere del total de 345.183 calculadas por el obispo Martí entre 1771-1784, aún cuando aquél hace clara referencia a la población total en materia de consumo de carne y chocolate. Es difícil, por tanto, saber qué porcentaje de la población estaba integrada al consumo mediante el circuito monetario. Para 1839, la población consumidora máxima la tenía el queso con 472.674 personas - un 53\% - si excluimos el cacao, que lo consumía toda la población. Y en 1873, excepto para el plátano y los granos, los demás productos tenían una población consumidora máxima de 446.000, lo que correspondía a un $25 \%$ del total.

A su vez, en la población consumidora las diferencias en el ingreso generaban diferencias en el consumo. Hacia 1839, de acuerdo a la información sobre el gasto personal en ropa proporcionada por Codazzi, sólo el $1,1 \%$ de la población gastaba $\$ 100$, el $3,7 \%$ gastaba entre $\$ 25$ y $\$ 50$, y el $83 \%$ sólo entre $\$ 1$ y $\$ 10 .{ }^{62}$ Es más que probable entonces, que un porcentaje escapara al deterioro de la calidad nutricional, ya sea por que tenían

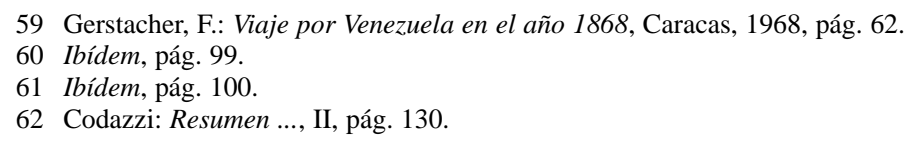


ingresos monetarios en cantidad suficiente o porque el autoconsumo total permitía una mejor alimentación. ${ }^{63}$

Es muy posible que la población integrada a los circuitos monetarios acudiera en parte al autoconsumo como consecuencia de la distribución del ingreso. El Táchira hacia 1873 era eje de un nuevo ciclo cafetalero exportador y de aumento del ingreso, con una fuerte concentración de éste pues sólo el 6\% de la población estudiada poseía el 58\% de la riqueza. ${ }^{64}$ En esta región, en la que la adopción del nuevo patrón de alimentación operaba en ausencia de una tradición de consumo colonial, dado su desarrollo urbano reciente, ${ }^{65}$ sólo esta situación distributiva podría explicar el bajo consumo cárnico ya señalado. Por ello, el $70 \%$ de esa población complementaba su alimentación con la caza y la pesca.

En otros términos, si bien no existen elementos para negar una tendencia secular al descenso en la calidad de la alimentación en el período considerado, en buena parte fundada en la caída del consumo de carne, desplazamiento del maíz y disminución de la masa ganadera, en cierta medida la población pudo haber escapado a sus consecuencias por la vía de la marginación del mercado. De hecho las informaciones, si bien señalan la disminución de este consumo en algunas áreas urbanas como Caracas, basándose en el número de animales faenados, como se ha visto, también apuntan a su importancia en la dieta básica en toda Venezuela: "Carne salada, carne frita, carne sancochada, tres veces al día, así reza el diario menú venezolano y su reglamento se cumple con el rigor más grandes". ${ }^{66}$ Aunque ya se conoce el ámbito de validez de tales creencias, afirmar su veracidad no invalida estas conclusiones, pues la provisión de carne por la vía de la caza y la pesca está bastante documentada. En 1818, en la llanura de Barinas, las familias llaneras "no corrían peligro de padecer necesidades, porque los viejos y los muchachos... eran capaces de abaste-

63 Actualmente la "agricultura de subsistencia" en América Latina permitiría un adecuado balance entre gasto energético y consumo calórico, si se considera que una familia de cinco personas puede alimentarse con dos o tres horas de trabajo diario. Ver Bergman, R.: "La agricultura de subsistencia en América Latina", en Alimentación, política y sociedad en América Latina, Super, J.C. y Wright, T. C., eds., México, 1985, págs. 133-162.

64 Torres Sánchez, Jaime: Ricos y pobres en el Táchira. La distribución de la riqueza en 1870, Venezuela, 1996, (en prensa).

65 Según el "Censo de Población de la Provincia de Mérida", el área de San Cristóbal tenía 12.939 habitantes en 1830. Ver Archivo del Consejo Municipal de San Cristóbal, Docts. Tomo I, 1830, leg. "Correspondencia y documentos de Mérida. 1830", s/fol.

66 Appun, K.: En los trópicos, Caracas, 1961, pág. 221. 
cerlas con largueza escogiendo de vez en cuando alguna ternera cerril en el rebaño próximo... ${ }^{67}$

En el Apure, no obstante la caracterización de extrema frugalidad de sus habitantes hacia 1850, se dejaba constancia de que los llaneros sabían preparar el pescado de muchas maneras, ${ }^{68} \mathrm{y}$ si bien algunas carnes de caza no gustaban, como el chigüire, ${ }^{69}$ la variedad aprovechable de éstas era muy grande. Por lo demás, es posible que buena parte de la cultura alimenticia indígena todavía hubiera sobrevivido en esa área.

Es probable, por tanto, que el deterioro de la dieta haya sido una tendencia real, pero que afectó básicamente a las poblaciones urbanas y a sus estratos de más bajos ingresos, que eran los mayoritarios, y en una proporción menor a la sugerida por las cifras. Los factores básicos explicativos de tal deterioro podrían asociarse a las fluctuaciones del ingreso personal y a los volúmenes descendentes de la masa ganadera, que en 1873 todavía no alcanzaba los niveles coloniales. Por ello, de acuerdo al análisis del Censo de 1873, la situación de la alimentación en algunas regiones era deficiente. En Monagas, había "falta de buena alimentación en los pobres", en el Distrito Federal era "insuficiente" entre los "pobres", en Trujillo "la gente pobre se ha conformado siempre supliendo las carnes y legumbres con un caldo salado condimentado con ají que hace servir de compañía a la arepa, al plátano, al cambur y las raíces y verduras de que usan como pan, añadiendo a este frugal alimento algunas jícaras de café 'bolón' o 'cerrero"'. En Ciudad Bolívar, los víveres se traían de otros lugares, lo que hacía "que la alimentación sea tan costosa que no esté al alcance de los pobres". ${ }^{70} \mathrm{La}$ apelación a la caza, la pesca y la agricultura de subsistencia pudieron haber sido los mecanismos que permitieron mantener los equilibrios alimenticios.

Es difícil evaluar la significación histórica de esta tendencia. En una perspectiva comparativa muy elemental, los niveles coloniales de consumo de carne aparecen como excepcionales. En Europa, desde 1550 hasta 1850 se redujo la ración de carne promedio y si se considera su consumo en París, entre 1751 y 1850, éste alcanzó entre 137 y 164 gramos siendo que el consumo medio para Francia fue, al comenzar la Revolución, de 55 gramos. ${ }^{71}$ Lo que, no obstante, era un consumo alto respecto a otras civiliza-

67 Vawell: Las sabanas ..., págs. 3-4.

68 Páez: Autobiografía ..., págs. 76-77.

69 Ibídem, pág. 227.

70 Vila: La geografía ..., págs. 84-88.

71 Braudel, F.: Civilización material y capitalismo, Barcelona, 1974, págs. 149-150. 
ciones, según F. Braudel. En Inglaterra el consumo de carne aumentó en el siglo XVIII hasta 1790, declinando posteriormente. De tal modo que en Manchester en la primera mitad del siglo XIX el promedio per cápita era poco más de 1 libra por semana. ${ }^{72}$ Eran estas diferencias las que tenía a la vista Humboldt precisamente, cuando anotaba en 1800 el alto consumo del producto en Venezuela.

En la América española puede hacerse una comparación con la Capitanía General de Chile. Desde 1655 hasta 1773 en la ciudad de Santiago la matanza de reses aumentó más de diez veces, cuando la población lo hizo cuatro veces en el mismo período. ${ }^{73}$ Esto podría indicar que el aumento de este consumo no sólo se dio efectivamente en Venezuela, sino que pudo corresponder a una tendencia en el ámbito de toda la sociedad colonial hispanoamericana. Más interesante por ahora es la información sobre la dieta de marineros de un buque mercante en 1703. Un total de calorías de 4.400 para una fórmula nutricional de [32,60 - 40,35 - 23,76], dieta calóricamente normal pero con un déficit de glúcidos, de acuerdo a los estándares utilizados. ${ }^{74}$ Otra dieta para marinos y soldados en 1768, proporcionaba 2.925 y 2.610 calorías alimenticias, insuficiente de acuerdo a los estándares, pero rica en prótidos como excesiva en lípidos. ${ }^{75}$

Evidentemente, estos últimos datos no corresponden a raciones medias propias de segmentos sociales amplios. Y, además, son raciones medias construídas y no raciones atribuidas, como los cálculos de este trabajo. Pero teniendo en cuenta estos aspectos y comparados los datos, las informaciones para 1775, si bien parecen suficientes desde un ángulo calórico, presentarían un mayor desequilibrio. En el contexto colonial y en relación a grupos que hacían esfuerzos físicos considerables como los marinos, la alimentación observada por Marón no parece tan excepcionalmente nutritiva como se desprendería de la comparación con los niveles europeos.

Otro problema consiste en sopesar el verdadero alcance de las observaciones típicas desde el siglo XVIII sobre la preferencia venezolana por la carne de res. En 1703, la dieta considerada proporcionaba 1.497,2 calorías proteínicas, la de $1768,555,9$ y 549,5 , para marinos y soldados respectiva-

72 Hobsbawm, E. J.: Trabajadores ..., pág. 409. Se trata de libras inglesas.

73 De Ramón, A.; Larraín, J. M.: Orígenes de la vida económica chilena. 1659-1808, Chile, 1982, pág. 78.

74 Ibídem, págs. 62-63.

75 Salinas, M.: "Raciones alimenticias en Chile colonial", Historia, N. ${ }^{\circ} 12$, Santiago de Chile, 1974-1975, págs. 57-76. 
mente, cuando para 1775 los datos para Venezuela dan 255,9. Tomando en consideración que en los tres casos los porcentajes de proteína animal son muy altos, los valores del caso venezolano no parecen tan excepcionales para una economía en que la masa ganadera había aumentado considerablemente en el siglo XVIII.

Es probable, por consiguiente, que la preferencia exacerbada por la carne de res advertida por las fuentes, no respondiera a preferencias relativas, sino a una situación de escasez relativa, inducida menos que por las disponibilidades de la masa ganadera que por los efectos de las fluctuaciones del ingreso para los sectores más amplios de la población. En el siglo XIX tal escasez se convirtió en absoluta por la caída del stock ganadero.

En conclusión, se desprende del análisis que el consumo per cápita de carne alcanzó un máximo en el siglo XVIII, lo que parece asociarse al aumento del ingreso y de la masa ganadera. El régimen alimenticio se articuló en torno a muy pocos productos, dependiendo en gran medida de una oferta generada por la agricultura de subsistencia. Su evolución secular, no obstante su estabilidad, parece adaptarse a los grandes cambios de la estructura económica. El régimen nutricional dependió de muy pocos productos aunque altamente nutritivos. La carne resultaba básica en el equilibrio alimenticio debido a su integración a los circuitos mercantiles, por lo que las variaciones del ingreso y de la masa ganadera pudieron tener un gran impacto en la dieta. La economía de conuco, la caza y la pesca, podrían verse como actividades económicas complementarias de gran significación para la reproducción demográfica. Por ello, el deterioro secular de la dieta podría haberse compensado en parte por la vía de la marginación de la economía de mercado. No obstante, su deterioro cualitativo derivado de la disminución de la masa ganadera y de la fluctuación del ingreso personal, parece bastante probable. 


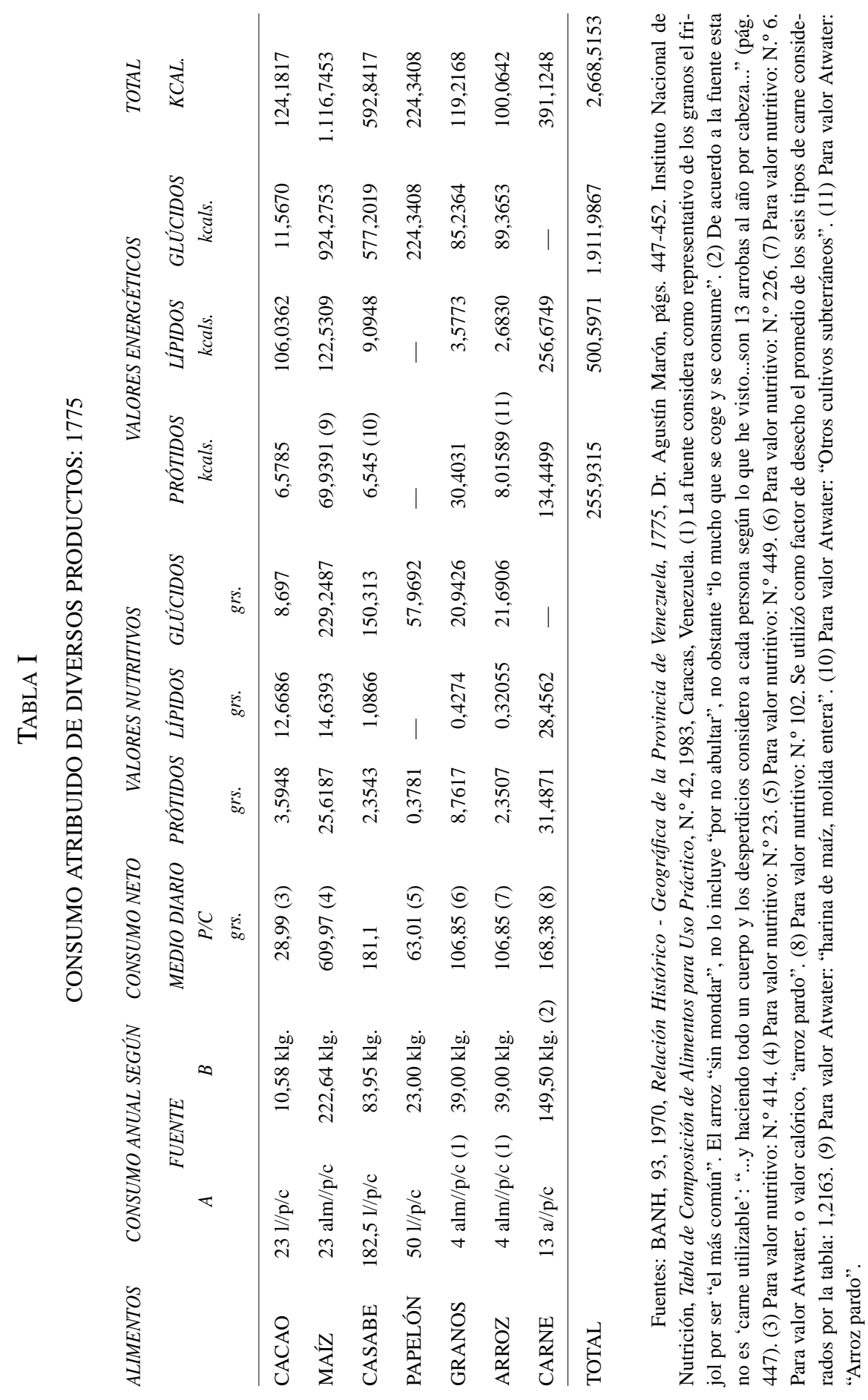




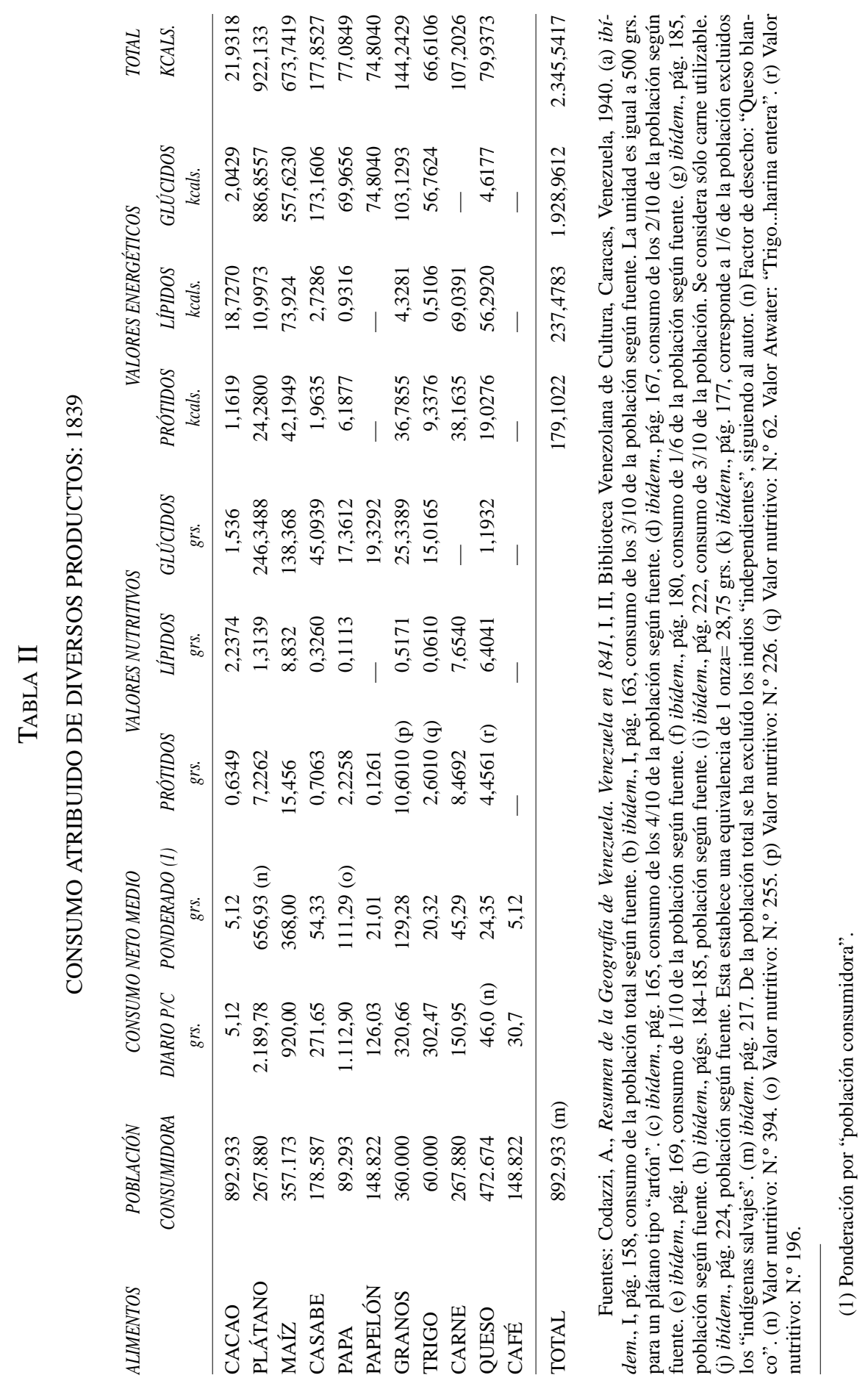




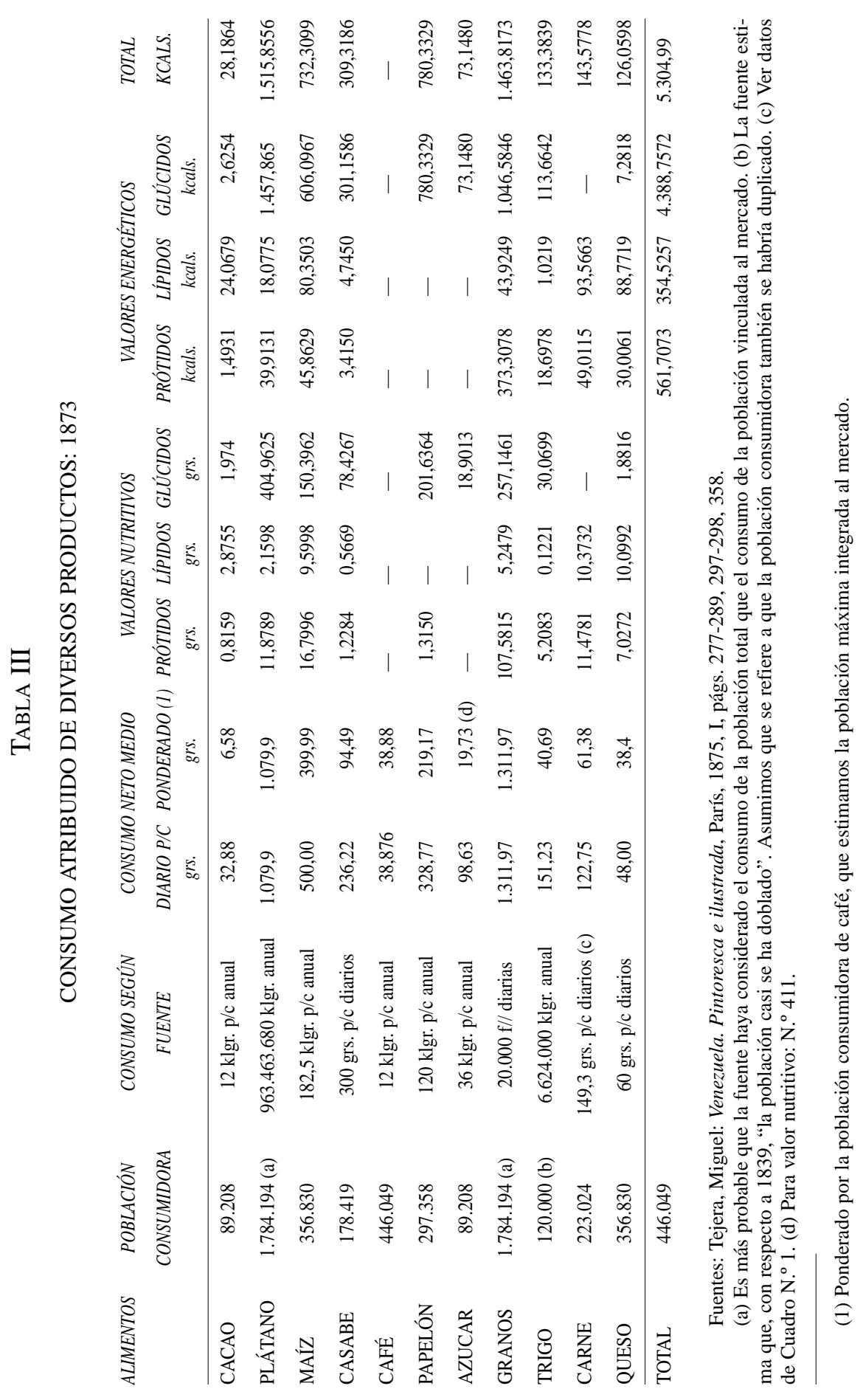

